\title{
Desarrollo, mito y discurso. La configuración del mundo de consumo a través del lenguaje
}

\section{Development, myths and discourse. The configuration of consume-world by language}

\author{
Gustavo Garduño y Robert Sting 1 \\ Recibido: 30-05-2017 - Aceptado: 07-08-2017 \\ DOI: https://doi.org/10.26441/RC16.2-2017-A10
}

RESUMEN: Con la modernidad los mitos pasaron de proveer un carácter trascendental al mundo a la adecuación permanente de procesos discursivos que permitiesen la legitimación del desarrollo como fin en sí mismo y la adaptación del individuo a una sociedad basada en la sucesión de satisfactores. Este texto expone las formas por las que el mito ha encontrado, en su relación con los objetos y con los consumidores, límites materiales, espaciales y temporales que debe superar mediante la permanente adaptación a través de mecanismos discursivos.

Palabras clave: mito; discurso; desarrollo; mercado; tiempo; espacio; mercancía; individualismo.

ABSTRACT: Myths have no longer a transcendental role since they have become related to the idea of progress (continuous change) and its legitimation in a consumer's society. In order to respond discursively- to the development conditions of market, myths have turn into mere scenarios to display merchandise. This paper explains some discursive ways myth has achived in order to provide sense for material, spatial and temporary limits of market societies.

Keywords: myth; discourse; development; market; time; space; merchandise; individualism.

1 Gustavo Garduño Oropeza es Doctor en Filosofía por la Universidad Autónoma del Estado de México, profesor del área de Comunicación y miembro del Sistema Nacional de Investigadores Nivel 1 en México. Su línea de investigación es sobre crítica del lenguaje y filosofía de la comunicación en la Facultad de Ciencias Políticas y Sociales. gustavoa.gardunoo@gmail.com, http://orcid.org/0000-0003-0403-5684

Robert Stingl es Magister en Filosofía por la Universidad de Viena, doctorante en humanidades por la Universidad Autónoma del Estado de México y profesor de carrera en el departamento de sociología. robert. stingl@univie.ac.at 


\section{Introducción}

Previamente al advenimiento de la modernidad, el trabajo en las sociedades de occidente se encontraba determinado gremialmente y estaba emplazado hacia lo estrictamente local. Los intercambios dependían de una materialidad que permitiese satisfacer necesidades de primer orden y se disociaban de cualquier perspectiva de futuro pues estas se consideraban atribución de quienes portaban la palabra y eran ajenas a la incidencia del cotidiano humano. En este contexto los mitos operaban como la única fuente de sentido y aparecían como una forma de justificación de las limitantes y sacrificios que el presente exigía en aras de un futuro idealizado, uno en que la vida podía pasar del plano terrenal a uno de eterna coexistencia con las deidades. Los hombres centraban el cotidiano en acciones específicas que operaban como una especie de requisito para la obtención de un objetivo último y que valía toda clase de carencias y sufrimientos en el presente.

El cambio apareció cuando ese telos u objetivo de vida trascendental se diluyó y la idea del futuro se modificó en virtud de las recompensas que los hombres podríamos obtener en el presente a través de nuestra participación en formas de producción que superaron la lógica de lo inmediato y se estructuraron en forma racional para enfrentar una escala de necesidades emergentes.

Esta mutación se dio como consecuencia de las revoluciones científica e industrial, del surgimiento de ideales desarrollistas y de la subsecuente expan- sión del mercado, que llevaron a creer que era posible obtener la redención en el aquí y el ahora y que las recompensas o satisfactores a las necesidades fundamentales del hombre podrían hacerse universalmente accesibles (y por lo tanto escalables). No obstante también reparamos en la paradoja que encerraba una forma de vida en la que todos pudiésemos obtener lo indispensable a costa del estancamiento de los medios para conseguirlo.

¿Y luego? ¿Qué vendría?... ¿Cómo podríamos mantener y, más aún, justificar el esquema de producción que ya se había puesto en marcha?

Fue entonces que el telos se modificó al anular la idea de trascendencia para suplirla por la de desarrollo: una especie de futuro que, en progresivo, permitiese conformar un permanente estado de necesidad/satisfacción basado en la voluntad del sujeto y apoyado por un proceso permanente de construcción escalable de nuevos requerimientos: la felicidad, la redención y el éxito. Todos ellos valores extraídos de la satisfacción de necesidades pero también modificados mediante la producción permanente de las mismas.

\section{La noción de Discurso}

Al no tratarse de un texto ni de semiótica ni de filología, para fines de este documento se apelará a una noción básica que toma al término como aquella dirección específica que adquiere texto en función de una idea o una intención. En otras palabras: se trata del resultado de un quiebre, de una desviación o un acotamiento a las 
posibilidades que el texto (escrito, material o icónico) presenta como un todo capaz de potenciar múltiples lecturas. De esta forma, el discurso acerca a una posición ideológica que atañe igual a la escritura verbal que a las derivadas de lenguajes arquitectónico, plástico, musical o, en forma más general, a la estructura social.

\section{La idea de Desarrollo}

Ideales del sistema capitalista contemporáneo como la productividad (o el hacer más con menos), la racionalización del trabajo (lo que hoy día se denomina tiempos y movimientos), el advenimiento de la hiper - especialización así como la tendencia al ahorro y a la inversión, tienen origen en la plataforma reformista del siglo XVI que condicionó las prácticas que los puritanos ingleses, holandeses y alemanes llevaron a cabo en el Nuevo Mundo. No es de extrañar entonces que, del análisis de las mismas, se pueda desprender una comparación entre las formas de producción que se daban en las colonias de Norteamérica donde el Reino de Dios se construía en el día a día y las diferencias de clase se mediaban por la capacidad productiva, los montos de participación y el ahorro y aquellas que caracterizaban a los virreinatos españoles donde la ética católica implicaba -contrariamente- una redención basada en la misericordia divina post-mortem como único remedio a un determinis- mo estructural insoslayable experimentado en vida (Weber, 2009).

La expansión capitalista protestante condujo al rediseño no solo de las formas de producción sino de las formas mismas de gobernar pues, para finales del siglo XVI, las grandes corporaciones alcanzaron dimensiones hemisféricas teniendo la posibilidad de actuar incluso a nivel naval, militar, técnico y hasta diplomático a nombre de sus metrópolis, llegándoles a hacer imposible el competir económicamente y reduciendo su papel al de meras entidades legitimadoras. En esta fase de la historia y paralelo al papel del estado, el capital condicionó las formas de hacer las cosas en las relaciones entre metrópolis y sus colonias ${ }^{2}$. Ejemplo de ello fueron las Compañías de Indias oriental y occidental en Inglaterra que hicieron de inmensas extensiones de territorio, centros de explotación multinivel de todo aquello que demandaba el progreso de Europa.

El término "Desarrollo" constituye el punto central sobre el que se articula la lógica del capitalismo. Tanto éste como su símil "Progreso" son vocablos lo suficientemente ambiguos para requerir su permanente redefinición y, por tanto, lo suficientemente maleables para ajustarse a evidencias de su presencia como herramientas para el acoplamiento entre la sociedad y los individuos. La idea de un avance permanente ha requerido la fundación de toda una mitología

2 Mismas que, terminados sus movimientos independentistas, se convirtieron en nuevos mercados para referencias europeas lo que implicó una emancipación sí, del poder estatal, más nunca del comercial. 
que permita intuir la no existencia del fin trascendental sino de una permanente adecuación de nuestro cotidiano a mejores condiciones. La lógica de que la acumulación (la cantidad) y de la panoplia (el ordenamiento o la distribución) han servido para consumarla, dotando al individuo de mecanismos de sentido y dimensiones rituales en las que su participación se da en forma de consumo. Mediante el acceso a las mercancías y encontrando para éstas nichos de acoplamiento, el consumidor experimenta la sensación de un cambio permanente pero también la de una continua aspiración a nuevas condiciones de vida que identifica, pero para cuyo acceso requiere de la adquisición de productos determinados.

De esta forma el mercado aparece como un espacio de liturgia en el que textos y prácticas convergen. Cada ámbito de la cotidianidad se prefigura como algo deseable, presentándosele además, a quien lo ha de experimentar, como un conjunto de condiciones para materializarlo a partir de opciones de consumo. De este modo para comer, para ejercitarse, para desplazarse, para entretenerse, para descansar, aparecen repertorios de prescripciones que solo pueden cubrirse mediante elecciones presentes en forma de oferta. La demanda aparece solo como consecuencia de la necesidad de acoplamiento del individuo al modelo.

Por ende "estar desarrollado" implica no solo "tener" sino que lo que "se tiene" obedezca a criterios de pertinencia y pueda ser distribuido en correspondencia con referencias establecidas por el propio contexto en desarrollo: el mercado.

Es a partir de la operación desarrollista que se hace necesario considerar la emergencia de una nueva forma de mitología; una que no se constituye a modo de un texto definitivo, críptico y trascendente sino de un relato en permanente escritura en el que la trascendencia es efímera y la realización escalable. Su forma actual: la publicidad o esquema narrativo mediante el cual el mundo moderno construye sus propios horizontes de trascendencia y genera los medios (costosos en relación con su disponibilidad) para alcanzarlos.

En la sociedad de consumo siempre hay más necesidades que bienes para satisfacerlas. Lo que esta sociedad produce en realidad, a través de la publicidad, son necesidades. No se producen bienes y servicios para satisfacer necesidades preexistentes, sino que se producen incesantemente necesidades nuevas y más variadas...(Ibáñez, 2012, p. 219).

La modernidad alteró la relación preexistente entre necesidad y satisfactor pues ésta solía ser inmediata y no se producía trabajo alguno si antes no se sentía el apremio por conseguir el satisfactor deseado; no había razón para interponer un mediador. Hoy la racionalización de los sistemas productivos opera en función de una oferta permanente de escenarios y ha derivado en una saturación de satisfactores que aparecen desvinculados de la necesidad y se dirigen más bien a compensar la distancia entre la idealización y los alcances de la mercancía. Por ello tiene que mediar un discurso. 
La innovación o toda modificación que introduce novedades en una estructura constituye un buen ejemplo para argumentar lo anterior pues opera sobre la naturaleza de un determinado satisfactor que, luego, se (re)introduce al mercado en virtud de un nuevo relato que deja en claro su mutación pero, sobre todo, las nuevas formas por las que permitirá al consumidor insertarse en un escenario prefigurado por la mercadotecnia y la publicidad.

a) Satisfactor ------ Innovación

b) Necesidad ------- Satisfactor

c) Innovación ------- Necesidad ... etc.

En medio de la serie de relaciones "satisfactor - necesidad" se encuentra un conocimiento complejo obtenido de las condiciones en las que se desarrollan los individuos en un marco de consumo específico como son el producto en sí mismo, la plaza donde se oferta, el precio al que se vende y el tipo de promoción que se le da.

Como puede leerse, una vez más la palabra desarrollo aparece como el móvil por el cual se considera a la satisfacción de necesidades como un proceso que se perpetúa mediante una permanente labor de producción de innovaciones aplicadas a la mercancía tanto en su dimensión material como discursiva. A través de cada una de dichas modificaciones se reajusta el esquema de expectativas y, así, los productos se transforman al parejo de los consumidores y los escenarios sociales a los que éstos aspiran.

En el proceso de permanente ajuste anteriormente descrito, el mito aparece como recurso de traducción mediante el cual el individuo comprende y se apropia de una nueva carencia o necesidad y modifica su espectro de expectativas.

\section{El mito emergente}

El mito fue referido por Ernst Cassirer (1988) como una forma simbólica constituida por el conjunto de explicaciones del mundo que no encuentra fundamento en el pasado sino en atribuciones ideológicas que se desprenden del temor, de la estabilidad, la admiración y el respeto a un entorno incomprensible.

Mythos en griego es sinónimo de leyenda y, como ésta, implica un relato fabuloso en el que la contingencia del entorno se ordena en función de la voluntad, el estado de ánimo y los procesos de relación mutua entre deidades. Éstas operan como analogía al hombre pero están revestidos de excepcionalidad para, así, servir de modelo a quienes se someten a su apreciación. El mecanismo por el que la naturaleza es traducida al contenido de dichos relatos es:

a) Trascendental desde el momento que propone un avance o tránsito del hombre hacia un estado o condición superior.

b) De índole moral pues supone la pre-existencia de una plataforma maniquea que relaciona lo que es bueno y malo con lo que es deseado e indeseado.

c) De índole épica pues reviste a las deidades con atributos que los humanos consideramos deseables pero inaccesibles. Fuerza, belleza, destreza, sabiduría y permanencia parecen ser características que distinguen a 
héroes y dioses en cosmovisiones tan distantes como las de Asia, Medio Oriente, Europa y América.

d) De índole selectiva pues establece parámetros para hacer distinciones sociales y privilegiar castas, sectores o prácticas en virtud de su capacidad para acercarse a las fuerzas divinas.

e) De índole ritual pues genera toda una serie de normas para que el hombre pueda establecer contacto con dichas fuerzas pero siempre en formas mediadas por una élite de sacerdotes. A la vez prescribe parámetros por los cuáles el participante en dichos ritos podrá moderar su actividad para que ésta sea consistente con criterios salvíficos o trascendentales $y$, consecuentemente, pueda avanzar hacia estadios superiores de existencia y conciencia.

f) Finalmente, de orden lingüístico pues el mito supondrá, por un lado, la reducción de las posibilidades de interpretación accesibles al hombre común (al establecer criterios de validez y veracidad sobre la experiencia) pero también, como propone Laclau (2014, p. 51-55) su ampliación al presentar la idea de un más allá trascendental que necesita adquirir forma.

Hoy es poco (pero contundente) lo que separa a los relatos modernos expuestos por la mercadotecnia y la publicidad de aquellos mitos fundacionales en las sociedades antiguas. Concretamente se trata de una distinción que separa a estos últimos como portadores de un carácter trascendental, ritual y prescriptivo que se contrapo- ne a la moderna función lingüística de reificar tecnologías, productos o servicios cuyas prescripciones no median en la relación del sujeto con sus semejantes sino en la que se teje con ellos mismos. La transformación de estas características míticas en virtud de nuevas concepciones históricas es lo que ha permitido hoy generar un nuevo esquema de concordancia ya no dirigido a las demandas de una deidad sino del dinero.

\subsection{Trascender permanentemente}

Si bien el mito permitió al hombre pre moderno soportar las privaciones cotidianas gracias a la promesa de un tránsito hacia un mundo mejor, los relatos expuestos por la publicidad y la mercadotecnia se han encargado de implantar la idea de que dicho mundo no es seguro pero que sus beneficios pueden ser accedidos desde el aquí y el ahora. En efecto: un mundo mejor supuso la creación de un discurso en el que la noción de "mejoría" se construyese sabiendo que entre más se tuviese, mayores podían ser las posibilidades de avanzar tanto a nivel personal como en lo tocante a lo comunitario. La mejoría implicó señalar que una ruptura de las diferencias de casta o clase era posible a partir de la oportunidad que se abría de trabajar y, mediante la entrega a la labor el hombre común se vería recompensado con dádivas otrora correspondientes solo a las élites: seguridad, salud, desplazamiento, diversión y educación aparecieron como garantía y la trascendencia se manifestó como evidencia material. Todo ello se hizo posible gracias al acceso universal al consumo. 
La moral que subyace en las promesas del mito moderno operó -igualmente- en forma maniquea trazando distinciones entre buenos y malos mediante la sustitución de las ideas primigenias de tabú o pecado por la de la negación del desarrollo mismo. Por otro lado, la virtud se construyó a partir de la noción de éxito o posibilidad de imponerse materialmente (riqueza) o simbólicamente (fama) al resto de la comunidad. Actualmente no puede haber peor blasfemia que la de negarse a participar en un mundo que abre las puertas de la salvación a cualquiera que esté dispuesto a pagar su entrada.

\subsection{Ritualizar la permanencia}

Pero garantizar la participación del individuo en esta nueva concepción mítica del mundo implica un proceso complejo en el que el sustento material para la producción y reproducción sociales se complementa con un sustento simbólico que las dota de sentido. El mercado aparece como el contexto litúrgico ${ }^{3}$ en el que individuos diferenciados por su nivel en la cadena productiva pueden hermanarse a partir de la posibilidad para consumir. El consumo aparece como el garante de desarrollo; como la actividad fundamental por la que se justifican el trabajo y la participación y hacia la que se dirige la esperanza.
Mientras exista la posibilidad de participar -como dice Baudrillard, (2012)en la liturgia, existirá la noción de que se avanza hacia algún punto; de que la consecución de metas es posible y de que el avance permanente puede erigirse sobre la formulación de expectativas generadas mediante prescripción de conceptos y prácticas "válidos" así como de la proscripción de los "no válidos" 4 . Es en medio de este proceso que la función mítica se fragmenta en múltiples relatos para generar escenarios tan diversos como las opciones de éxito comercializables y las propias condiciones adquisitivas de los individuos que se suman a la gran liturgia.

El proceso seguido puede leerse análogamente a las posiciones trazadas por Foucault (2002) sobre la apropiación del poder y la exclusión. En ambos aspectos un acoplamiento al moderno esquema de cambios permanentes es requerido; primero para que la sociedad reconozca una nueva moral basada en el éxito y el fracaso y, luego, para que el individuo las reconozca, se realice en función de ellas y se ostente como prueba empírica de las transformaciones prometidas por el progreso ante los demás.

El individuo moderno trasciende, de este modo, su posición dependiente de un discurso teocrático e ineludible hacia la posibilidad de un nuevo

3 Liturgia como el conjunto de prácticas prescritas por un culto involucrar a los participantes en el sentido de un mito o credo.

4 "Éxito" vs "fracaso"; "victoria" vs "derrota"; "riqueza" vs "pobreza"; "ganadores" vs "perdedores"; "gente productiva" vs "improductiva" o, peor aún: "parasitaria". No es difícil seguir -mediante esta lógica- que el segundo proceso externo de exclusión que enuncia Foucault, o sea el de la locura, aparezca en forma casi automática escindido de la normalidad señalada por el polo izquierdo en cada oposición. 
esquema de relación y trascendencia que dependen de su participación en las diferentes vías para la producción y reproducción de una retórica del trabajo, del desempeño y del éxito. En efecto, dejó de estar a merced de Dios pero, ahora, pasa a depender de su involucramiento en el trabajo para alcanzar al dinero.

La prescripción que dicta el desarrollo resulta clara y marca pautas para que cualquiera pueda llegar a SerTeniendo pero suponiendo, claro está, compromiso y esfuerzo. Compromiso para seguir a pie-juntillas las condiciones que el sistema de mercado expone a través del discurso maniqueo del éxito y el fracaso y esfuerzo para seguir el camino "adecuado" en el ascender en la escala social y en la obtención de un cierto nivel de diferenciación con respecto a la masa sin referencia.

Parece curioso pero el modelo desarrollista pide de entrada el sometimiento a pautas de desempeño económicas, tecnológicas, sociales $\mathrm{y}$ culturales para, luego, ofrecer vías de distinción en función del grado de cumplimiento de las mismas. Uno puede avanzar solo en la medida en que sea consistente con la prescripción que dicta el discurso del sistema.

\subsection{Asegurar la permanencia (una nueva forma de trascender)}

La moral de base y la racionalidad del mundo moderno de consumo dejaron de estar basadas en las oposiciones entre bondad y maldad o verdad y mentira. Las acciones cotidianas del individuo pasaron de ser producto de la adaptación a carencias y necesidades coyunturales para convertirse en derivados de la consistencia entre una aspiración estructuralmente referida por el funcionamiento del sistema (en tanto mecanismo de inclusión/exclusión) y el propio reflejo individual en el espejo de lo social proyectado adnauseam a través de medios y de una industria cultural en expansión.

Es a partir del punto anterior donde el lenguaje pasa a cobrar un rol fundamental al constituir el mecanismo por el cual se da la doble relación entre las formas de integración y de diferenciación del individuo al interior del entramado del sistema.

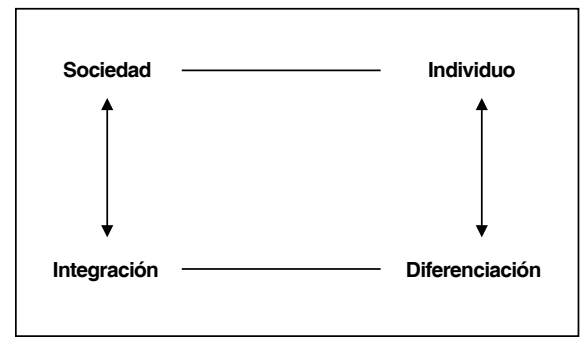

Al referir "Sistema" se pretende caracterizar la relación por la que cada oposición horizontal en el esquema opera como referencia semántica para tomar una decisión y se presenta generando cambios ya sea mediante la integración a un grupo, sector o clase específicos 0 , contrariamente, mediante la diferenciación al interior de ellos por vías de la capacidad, el rendimiento, el mérito u otros indicadores. 


\section{El discurso y la construcción social del desarrollo.}

Para Foucault ninguna forma de discurso opera sin procedimientos de exclusión que, basados en una voluntad de verdad, determinan lo que resulta normal y anormal, permisible y prohibido o deseado e indeseado al interior de un sistema social. Para el pensador francés es en función de los límites entre estas posiciones dicotómicas que se acepta o excluye a los saberes y se opera en conformidad con niveles institucionalizados e históricamente válidos.

Hoy el discurso emanado del mercado opera al pie de la letra pues, por un lado, prescribe escenarios verdaderos o válidos a los que se asocian las ideas de "éxito", "reconocimiento", "autoridad", "belleza”, "fortaleza", "salud", "bienestar" y, por otro, proscribe sus contrapartes haciendo que el consumidor genere su plataforma cognitiva en función de elecciones tendientes a llevarlo más hacia la arista positiva $o$, por lo menos, alejarlo de la negativa.

En la era del mito del desarrollo esta "separación que rige nuestra voluntad de saber" aparece en forma de un sistema de exclusión basado en "pertenencia" y "relevancia": precisamente los términos que refieren el nexo indispensable entre el individuo y su grupo pero también entre la posibilidad de sobre salir dentro de ese último a partir de las decisiones hechas por el primero entre las ofertas del mercado. De esta forma credo, elección profesional, actividad, valores, relaciones interpersonales, entretenimiento, régimen alimenti- cio y un sinfín de premisas más aparecen como ejemplo de las formas válidas o verdaderas para integrarse. Integración que dependerá del grado de dominio que el individuo tenga de las normas propias para cada caso (conocimiento).

En diferentes marcos del desarrollo se operará discursivamente en conformidad con actos ritualizados, eficaces y justos de enunciación dirigidos al enunciado mismo: hacia su sentido, su forma, su objeto y la relación con su referencia (Foucault, 2002, p. 20)

Ahondemos en el caso de la elección profesional. Ésta no es en ningún sentido consecuencia de una decisión libre sino de una selección basada en una oferta instituida y consistente con la necesidad misma de operación del sistema, que obliga al sujeto a realizarla en función de una serie de perspectivas pre-constituidas por el discurso y conlleva la idea de una remuneración, un tiempo, una cierta dificultad, la posibilidad de ascenso en un escalafón, el tiempo libre, el compromiso y un largo etcétera que permitirá al individuo conocer anticipadamente las formas por las que habrá de competir en un esquema de mercado del desarrollo profesional; es decir el esquema de prescripciones y recetas hechas exprofeso para tal fin. Pero esto ocurre en todos los niveles del cotidiano y hace parecer que cualquier libertad ejercida por el individuo radica en algo similar a transitar entre una serie de pasillos tremendamente amplia, pero limitada, de un supermercado para el cual no existe salida. 
El caso de las relaciones interpersonales no es disímil en lo absoluto. Implica igualmente un proceso de selección realizado sobre una plataforma previamente establecida de criterios para seleccionar: estereotipos físicos, mentales, actitudinales, profesionales, raciales y económicos que guían al individuo hacia escenarios por conocer; escenarios de éxito, fracaso y, por lo tanto, de relevancia dentro de un grupo o filiación ideológica. La voluntad de conocer es determinada por una previa necesidad de verdad.

El orden de discurso en Foucault implica un segundo proceso de exclusión que no parte de los determinantes exógenos, sino de su propia lógica de articulación. El primero de ellos se refiere al "comentario" entendido como el efecto de repetición ritualizada o la imposibilidad de seguir una línea distinta a la prescrita por el discurso (mito fundacional mismo) bajo una lógica de coherencia. En este punto, el loco (impío, apóstata, hereje) es aquel que no puede seguir una argumentación y se pierde bajo los efectos de una a-sistematicidad, desorden y caos y es, consecuentemente proscrito.

“...El comentario conjura el azar del discurso al tenerlo en cuenta: permite decir otra cosa aparte del texto mismo, pero con la condición de que sea ese mismo texto el que se diga, y en cierta forma se realice [...] Lo nuevo no está en lo que se dice, sino en el acontecimiento de su retorno". (Foucault, 2002, p. 26)

Hoy día las redes sociales aparecen como un perfecto ejemplo para comprender la forma por la que el discurso queda condicionado a temáticas -comentarios- sobre los cuáles se restringe la participación a meros puntos de vista que bordan un mismo asunto presentado. Los circuitos de la moda, por igual, marcan lo que denominamos tendencias y estas fungen operan como prescripciones de liturgias temporales o verdaderos mecanismos de exclusión para todos aquellos que o las pasan por alto o no tienen un dominio de su retórica que les permita insertarse en ciertos grupos y, luego, poder destacar dentro de ellos.

Un segundo elemento interno de exclusión es la "cuestión autoral" en la que el discurso se presenta como un marco de dominio específico o eje de agrupación de una serie de enunciados que se subordinan a un orden superior. "El autor es quien da al inquietante lenguaje de la ficción sus unidades, sus nudos de coherencia, su inserción en lo real." (Foucault, 2002, p. 26). Una especie de interpretante que sirve como validación basada en la coherencia.

El sistema de mercado es un aparato de referencias autorizadas por su mismo discurso. La mercadotecnia a través de elementos como el "prestigio", "la marca" o "la moda" ha eliminado prácticamente la posibilidad de pensar en parámetros de verdad ajenos a los que el propio enunciado publicitario de temporada emite $y$, no importa cuán grave sea la red de consecuencias semánticas y pragmáticas del mismo, la mera opción de una adecuación de las posibilidades del receptor a los escenarios difundidos por el aparato mediático basta.

Lo anterior implica -como sucedía en tiempos premodernos- que la cons- 
trucción del mito y su correcta expresión bastaban para involucrar mediante el ritual a todo un pueblo necesitado de explicaciones trascendentales. Para autores más moderados (que considerarían a la mercadotecnia y a la publicidad como la enunciación de meras opciones para la satisfacción de necesidades) esto resultaría escandaloso pues estamos afirmando -sí- que el mito es, nada menos, que una forma de manipulación para la cual no existe salida. En este contexto, las instituciones encargadas de enunciarlo en forma de relatos diferenciados (pero siempre proclives a mantener el objetivo central de expandir el capital) devienen en autoridad incuestionable; en artífices de su propia verdad validable a través de una experiencia inducida al individuo a través del recurso de la analogía con cualquier situación publicitada.

La construcción del "Yo" a partir del consumo es la prueba de una verdad suprema alcanzada, la evidencia incuestionable de que las premisas y las promesas del mercado están funcionando y que todo el proceso de desarrollo se manifiesta en nuestra persona $y$ en nuestro cotidiano.

Del mismo modo que los mitos premodernos exigían una "Fe Ciega" a sus profesantes, los mitos actuales la fortalecen mediante evidencias en las que los "hechos" encajan a la perfección con "los relatos" pues aquellos son consecuencia de un discurso que aparece en forma de necesidad construida. Las liturgias del mito moderno permiten gozar de los beneficios del consumo pero no cuestionar los motivos para el mismo, pues no los hay. Va implícita la posibilidad de formar parte del relato publicitario mediante la adecuación entre la referencia discursiva, el consumo personal y su impacto en nuestra cotidianidad, producto mismo de la pantalla o del espectacular urbanos. El mito moderno se valida en los espacios de vida diaria mediante el diploma colgado en la oficina o el birrete de la graduación. Implica la perspectiva de la despensa con lo "necesario", del animalito en casa o la cirugía estética que enmascare nuestra imperfección y nos acerque a las referencias mediáticas en boga... Una vez que se tiene acceso a todo ello, sabremos que estamos en la ruta del éxito y lejos de la del fracaso. Sabremos que nos estamos desarrollando.

Son precisamente dichas oposiciones (éxito y fracaso) trazadas por la estructura proposicional de discurso, las que condicionan el cotidiano, materializándose a partir de referencias que circulan a gran escala, hermanando comunidades antes disímiles que se asientan en una misma idea sobre lo que es y no importante, trascendente y, sobre todo, validable. Mediante dicho esquema formalizado de oposiciones es que se obtiene parámetros para el verificar el avance personal o el desarrollo colectivo $y$, de esta forma, se hacen ostensibles o comunicables al interior del marco de esa "Aldea Global" de la que hablaba McLuhan (1989).

\subsection{Reconfiguración del tiempo}

Pero un logro, una adquisición o un avance institucionalmente reconocible 
no pueden permanecer estables por mucho tiempo pues pasarían de ser un factor para la verificación del desarrollo a convertirse en un asunto de estancamiento y éste último es un término proscrito. No puede haber permanencia pues ella implica ya dejadez, incapacidad o lo que hoy coloquialmente se denominaría permanencia en la "Zona de Confort", un interesante recurso discursivo de carácter disuasorio que motiva al individuo a mantenerse en un estado de esfuerzo permanente.

El enemigo en este caso es el tiempo y el consumo tiene como una de sus metas más claras aprovecharlo para su propia reproducción: Desde el establecimiento de horarios laborales, la señalización de edades óptimas para la obtención de grados académicos, la señalización de temporadas para la moda, y el establecimiento de parámetros para la productividad hasta llegar a la prescripción de lo que se "debe hacer" con el tiempo libre, nos encontramos frente a una cultura del corto plazo y éste nos ha contaminado a tal grado que somos dependientes de una obsesión más dirigida al cambio en sí que a la esencia de aquello en virtud de lo cual cambiamos. Somos, en cierta forma, recurrentes con la metáfora del niño que -en un centro comercial- pide a gritos un juguete que, al obtenerlo, olvida o en el mejor de los casos usa someramente, para luego arrojarlo en el abandono. En este contexto no importa ya el objeto en sí, sino el poder que el acceso al mismo nos confiere. El enemigo a vencer es la permanencia en un mismo punto, la continuidad espacio- temporal: el sedentarismo consumista o la apatía ante el cambio.

"El que no tranza no avanza" reza un refrán mexicano en el que podríamos extender el sentido de "la tranza" desde su significado original de engaño hasta la noción más amplia de "intercambio" o "trueque" que se hacen a manera de engaño o trampa.

\subsection{Reconfiguración del espacio}

$\mathrm{Al}$ igual que el tiempo, el espacio ha tendido a reducirse y en la "Aldea Global" hasta lo más identificado con lo local se mercantiliza. El espejo o portal que representa la tecnología, al acelerar los tiempos para el desplazamiento físico, ha acortado la geografía haciendo de los espacios un objeto más de programas subordinados a una lógica de consumo de la que ni siquiera escapan elementos antes identificados con la tradición, el folclore o lo autóctono. El espacio ha sido etiquetado por y para el mercado y el discurso lo ha convertido escenario para la realización de actividades productivas, de recreación, de aprendizaje o de socialización relacionadas con el consumo global. Las guías culturales, la gastronomía, los decretos sobre "pueblos mágicos o con encanto", las eco-rutas, son ejemplos de lo anterior.

No hay geografía que no tenga un discurso que la convierta en atractiva o pertinente, en inadecuada o en riesgosa, en deseable o en evitable, en accesible o inaccesible; pero que, además, la relacione con medios para la realización de dinámicas o actividades específicas.

El espacio implica un programa, es el lugar significante y por ello puede 
prescribir y proscribir en conformidad con los intereses del mercado. De hecho, en el marco de las relaciones intersubjetivas, los espacios se vienen adecuando a modelos estandarizados que permiten una mejor integración a lo colectivo.

De esta forma los modelos generales que siguen los conglomerados urbanos aparecen estandarizados en cada hogar, en cada oficina, hotel, comercio o vía para el desplazamiento. Uno viaja a la playa en busca de exotismo, libertad o de vuelta a lo básico, pero sin alejarse de las ventajas de dicha estandarización: seguimos usando un retrete, una ducha, nos refrescamos con aire acondicionado, navegamos en internet y no tenemos que ir a buscar nuestros alimentos pues estos están a disposición en algún restaurante. Vacacionar en la playa implica una idea triste: la de un mero desplazamiento formal de nuestros espacios que permita mantener nuestro sometimiento a los contenidos...

\subsection{Reconfiguración de la materiali- dad del objeto en signo}

Pero quizá el mecanismo de reconfiguración más importante en términos de discurso sea la que experimenta el objeto de consumo en sí mismo. Y en este caso no se trata de un cambio en término de relaciones económicas (costo/precio) sino de modificaciones a nivel de la propia ontología, como parte de una red de relaciones complejas.

$\mathrm{Al}$ hacerse discurso todo producto o servicio (actor) se vuelve, a la vez, diálogo e implica una serie de propiedades independientes a su mera función, lo que lo hace comunicacionalmente activo $y$, por lo tanto, susceptible de vinculación semántica con una red de diferentes sectores de la sociedad, de otros productos o servicios o de diferentes nichos de consumidores (todos ellos actantes). En esta condición se basa la ecología de consumo de la que habla Baudrillard (2012, p. 3) y la conformación de una sociedad en la que las estructuras y sus modificaciones ya no dependen en exclusiva de los sujetos sino de los objetos y acciones relacionadas. Y es que lograr cambios en la concepción del tiempo y el espacio implica relativizaciones verificables en lo material o en lo concreto, dimensiones que implican directamente a los objetos y a su red. Mediante dichos cambios es que podemos verificar mutaciones por acumulación, pero también por mediación en la medida en que cada uno depende de otros objetos pero también, por el contrario, los hace depender de su presencia para poder accederlos. Los objetos en una sociedad de consumo son los signos que estructuran y modifican el discurso. En ellos se basa la red necesaria para establecer distinciones, jerarquías, relaciones y funciones, pero también relaciones mutables que impliquen la permanente adecuación (espacio temporal) que supone el desarrollo. Como signo, el objeto de consumo es en sí mismo dinámico y sus variantes operarán a su interior mediante modificaciones en el plano de la forma o del contenido. Parafraseando a Marx y Engels (1974): Al cambiar la forma de los materiales, nosotros también cambiamos. 
Tomemos el caso paradigmático del automóvil (cuya evolución desde fines del Siglo XIX no ha cesado de operar drásticamente a nivel formal pero muy levemente en términos de contenido) ha traído toda una serie de modificaciones en su red de relaciones que lo hacen ver como un indicador de progreso en múltiples niveles: social, económico, tecnológico, social y cultural, al grado de que hemos hecho depender las dimensiones espacio - temporales de nuestros centros urbanos de su existencia misma. Para seguir con la idea de Baudrillard (2012) de una ecología del objeto, el automóvil es uno de los pilares de nuestro sistema de vida y, como signo, es capaz de operar cambios formales y de contenido en el discurso que se teje sobre el mismo. Ejemplo de lo expuesto es la política de prohibición que, en desde los años veinte y hasta nuestros días, ha condicionado la posibilidad humana para tomar decisiones sobre el desplazamiento en las calles: se trata del llamado jay-walking que, según el diccionario Oxford (2010, p. 831), implica la "acción ilegal de cruzar o caminar a lo largo de la calle sin tener cuidado de evitar el tráfico". Esto implica una prescripción a la vida humana desde la tecnología ya que esta última queda situada discursivamente en un nivel jerárquico superior al de la propia libertad humana para moverse peatonalmente y en conformidad con su necesidad. Hoy día muy pocas personas cuestionan este criterio e incluso lo con- sideran sensato dentro del esquema de vida urbano. El automóvil es insertado en la vida urbana gracias a un discurso que, por una parte, impacta la forma por la cual debemos movernos y, por otra, nos sitúa en un esquema de racionalidad, privilegios y prioridades como es la movilidad.

¿Qué pasa, sin embargo, si al esquema de prescripciones que da el automóvil a los jay-walkers interponemos la idea de una movilidad a escala humana ${ }^{5}$ ? Hay una transformación en términos de la relevancia que cobra el objeto (automóvil) como parte estructurante del discurso de la red de relaciones concernientes a movilidad y se genera una controversia o proceso comunicativo en el que los actantes debaten sobre pertinencia en diferentes niveles (Mobile lives forum, 2011). El discurso condicionado por el objeto se vuelve político.

\section{El consumo y sus paradojas a través del discurso.}

Uno de los problemas que presenta el discurso en su dimensión publicitaria (y prácticamente en cualquier otra) es que desvincula al receptor del resto de las posibilidades de lectura al interior de lo que podríamos llamar un texto social, acercándolo a un determinado nivel de comprensión que está basado en elementos como la inmediatez, la extensión, la espectacularidad y la simplificación (ideológica). Dichas condiciones de la enunciación son las que

5 Mayor información sobre este paradigma emergente en el sitio Ciudad en movimiento (2014). 
permiten una rápida lectura e identificación de las promesas publicitarias por parte de las audiencias y la consecuente aspiración que conlleva al consumo.

Pero el sesgo descrito supone una serie de consecuencias sociales cuya manifestación aparece revestida de paradoja o ironía cuando el discurso pasa a operar más como referencia para evaluar la disociación entre el objeto de consumo y la vinculación que éste tiene con sus diferentes niveles de reificación.

El pensador austro-mexicano Ivan Illich (2015) denomina a este hecho "contraproductividad" y lo relaciona como el efecto contrario emanado de la saturación de productos/servicios (heteronomía) en relación con los beneficios esperados por sus propietarios (autonomía). Siguiendo a este autor, el caso del automóvil resulta interesante al constituirse discursivamente como un condicionante para la articulación de un conjunto de adecuaciones contextuales (desde lenguajes de tráfico hasta códigos de identificación de marca) pero también para una permanente adecuación del discurso que se teje sobre la tecnología misma y que lo ha llevado a volverse un indicador de desarrollo industrial. No obstante, el éxito que ha cobrado el vehículo automotor como factor para la expresión de desarrollo (personal-social) aunado a su proliferación en que el mercado ha conducido una serie de paradojas constituidas primero por la expectativa que generan los discursos de la velocidad y la comodidad que se ven no solo revertidos sino anulados (en forma de inco- modidad y lentitud) cuando las calles se saturan, el tráfico provoca un nulo avance y comienza a faltar el espacio para el aparcamiento.

El automóvil resulta ser entonces contraproductivo pues su propio éxito anula las perspectivas discursivas (el mito) que los publicistas y mercadólogos generaron. "La reorganización del espacio a favor del motor vacía de poder y de sentido la capacidad innata de moverse." (Illich, 2015, p. 347)

El discurso que se ha generado para avalar la difusión social del automóvil lo ha consagrado como parámetro de verdad en la configuración de tiempo, de espacio y de otros objetos al ser el punto de partida para determinar horarios, distancias y las formas que adopta la infraestructura urbana -aún a costa del propio Ser humano-. Y es que la retórica en torno al auto ha tenido como eje -desde principios del siglo XX- a la velocidad o la posibilidad de recorrer más distancia en menor tiempo. Esto ha llevado a un rediseño completo de los centros urbanos y a la disociación entre mundos de vida (se trabaja en puntos muy alejados de aquellos en los que se habita) y a su conexión mediante redes de concreto que tienen que ser ampliadas, incrementadas y rediseñadas a fin de mantener aquella inicial promesa de ahorro en tiempo. Paralelo a la modificación en las concepciones de tiempo y espacio aparece todo un lenguaje de ingeniería que habilita, contiene y modifica materialmente a la ciudad para que "la Verdad" del automóvil prevalezca. 
Por las noches el usuario sueña con lo que los ingenieros le sugieren durante el día a través de la televisión y las columnas pseudo-científicas de los diarios. Sueña con redes estratificadas de vehículos de diferente velocidad que convergen en intersecciones donde la gente puede encontrarse en los espacios que les conceden las máquinas. Sueña con servicios especiales de la "red de transporte" que se harán cargo de él definitivamente (Illich; 2015, p. 339).

Viéndolo en un sentido mítico: La verdad absoluta en materia de movilidad es la que se desprende de la propiedad y el manejo del automóvil. El gran relato que se teje en torno a él margina a otros actores (peatones, ciclistas, transporte público) mediante argumentos supremacistas que buscan arrogarse el derecho al privilegio de uso exclusivo de las calles. Bajo el efecto del discurso imperante, incluso la muerte no resulta imputable al automóvil bajo la excusa de que toda la infraestructura urbana tiene que ser coherente con su operación. Pensemos por ejemplo en los puentes peatonales que garantizan la vida del ser humano siempre y cuando éste no aparezca como un obstáculo a la promesa de velocidad adjudicada al automóvil. Si una persona muere debajo de un puente peatonal es que rompió la prescripción del mito y ahora puede debe serle adjudicada su culpabilidad. Pero ¿debe ser necesariamente así?

Otro ejemplo puede ser el del "teléfono inteligente" que aparece como un dispositivo que igual impacta en términos temporales, espaciales y materiales desde que garantiza una posibilidad de respuesta inmediata primero a un diálogo o, luego, a un conjunto de instrucciones en diversos formatos o aplicaciones (apps).

El efecto contraproductivo que atañe a este último ejemplo comienza a manifestarse prácticamente en todas las dimensiones de la vida cotidiana del hombre. Éstas aparecen enteramente mediadas por los dispositivos de comunicación que, incluso, han sido llamados "inteligentes" y vienen presentando problemas como el de la limitación del impacto de la comunicación humana en términos impersonalidad, superación de barreras espacio - temporales (lo que suprime una gran cantidad de contenido contextual) e incluso de la progresiva reducción de contenidos, mismos que se fueron clausurando gracias a los filtros que el código o la plataforma expresiva impusieron.

Los teléfonos inteligentes nos han enseñado a vivir restringidos a una especie de repertorio preestablecido para el uso del lenguaje mismo.

\section{Concluyendo: Las nuevas dimensio- nes del mito y el vuelco al individua- lismo:}

La tecnología cumple sus objetivos desmontando el mundo y volviéndolo a montar de modo productivo.

Langdon Winner

Nos damos licencia de sustituir el término tecnología por el de objeto de consumo pues, al final, éste no es otra cosa que un derivado de la capacidad transformadora del hombre avalada por el discurso que éste se verifica en el 
mercado en función de una permanente adecuación entre la reificación del producto-servicio y la superación de la escisión entre reificación y el uso. En esta relación el mito pasa a cobrar un carácter dinámico y de permanente transformación que permite al individuo jugar con el doble proceso de pertenecer y diferenciarse socialmente pero a partir de sus consumos. Al perderse el enfoque trascendental que tenía en el mundo pre-moderno, el mito se configura como un texto en permanente escritura que busca a la vez ser coherente y romper dicha coherencia para habilitar el flujo permanente de la identidad del consumidor en sus contextos de relación e insertándolo en la idea de desarrollo mediante la adecuación del tiempo, el espacio y la materialidad.

Como se vio en el ejemplo precedente donde se abordó el caso del automóvil, el mito que lo reifíca no ha terminado de escribirse y hoy busca un giro discursivo que le permita superar evidencias contradictorias en el contexto contemporáneo de urbes colapsadas en las que la posesión de vehículos ha dejado de implicar velocidad, acercamiento y confort. Por ello, el rediseño de las ciudades, la creación de programas de contingencia, el costo del aparcamiento, la ampliación de infraestructura e incluso la emergencia de automóviles movidos por energías alternativas aparecen como respuestas que la propia técnica desarrolla buscando garantizar que el consumo se mantenga y, con éste, la vigencia del mito (o ver- dad). A saber: Que "el automóvil está para quedarse".

En el momento en el que una sociedad se hace tributaria del transporte, no solo para los viajes ocasionales sino por sus desplazamientos cotidianos, se pone de manifiesto la contradicción entre justicia social y energía motorizada, libertad de la persona y mecanización de la ruta (Illich, 2015, p. 335).

$\mathrm{Y}$ es que toda premisa discursiva impacta en la medida en que se vuelve consistente con la operación del mito en el corazón del sistema. Langdon Winner, experto en sistemas sociotécnicos lo refiere así:

...a medida que las tecnologías se construyen y se ponen en uso, ya se están produciendo alteraciones significativas en los patrones de la actividad humana y de las instituciones humanas. Se están creando nuevos mundos. No hay nada de secundario en este fenómeno. De hecho, es el logro más importante de cualquier tecnología nueva. La construcción de un sistema técnico que involucre a seres humanos como parte de su funcionamiento requiere de una construcción de los roles y las relaciones sociales (Winner, 1987, p. 27).

Ante la construcción referenciada de dichos roles y en virtud del condicionamiento que sufren las relaciones sociales gracias a la mediación de las mercancías, el ser humano aparece en la era del consumo como una criatura emancipada de sus semejantes que ha pasado a depender de básicamente de sus relaciones con los objetos y su escenificación en el 
mercado. En esta "nueva ecología" el tiempo y el espacio se diluyen para habilitar una inmediatez que, basada en la capacidad adquisitiva, da la pauta para pensar en la progresiva construcción de un crecimiento personal -un desarrollo-. La figura emergente del "consumidor" es la de la nueva unidad cultural que se compromete con la posibilidad de mantener su propio desarrollo a costa de "lo" demás y de "los" demás sin necesidad de referencia trascendental. Desde esa perspectiva:

a) Los mitos pierden su carácter de referencia de vida y reaparecen como formas discursivas tendientes a generar reificaciones sucesivas. Éstas, como derivados modernos, asignan una dimensión semántica tanto a productos como a servicios y operan como formadores de un logos (Cf. Laclau, 2014, p. 54).

b) Las reificaciones constituyen mitos modernos efímeros que no implican ya la ambigüedad de un Dios sino que llenan con evidencia la indeterminación semántica del concepto de desarrollo y lo ajustan a mercancías mediante la maleabilidad pragmática del dinero.

c) Lo anterior hace suponer que el mito -hoy- se sujeta a condiciones internas y externas del discurso. Internas porque opera en función de sus propias limitantes formales y referenciales y, externas, a causa de su relación con objetivos de instituciones $\mathrm{u}$ organizaciones (estos últimos entendidos como formas de validación derivadas de un orden consensuado). d) El discurso funge también como puente entre los mecanismos de transformación tecnológica y los patrones de actividad humana a través de instituciones (laborales, familiares, de creencia y de entretenimiento) que cubren el rol de habilitadores y condicionantes del desarrollo personal a través de la aceptación de dicha transformación. "Acordamos por whatsapp" "Entramos en conferencia a las 12:00 vía Skype" "Solo circulan vehículos eléctricos".

e) El discurso y su dimensión reificadora ha permitido la aceptación del hecho que la tecnología puede generar por sí misma nuevas "formas de hacer" y que éstas pueden eventualmente cambiar la dinámica de relación espacio - temporal ajustando conceptos como "inmediatez", "tiempo real", "en vivo", "limpio", "cero emisiones" apareciesen como prescripciones para la forma de realizar ciertas prácticas y revestirlas de "veracidad" o, al menos "legitimarlas".

f) Los conceptos anteriormente expuestos pueden a su vez condicionarse mutuamente a modo de generar sistemas que permiten la verificación de la operación de los actores en virtud del espacio, del tiempo y de la pertinencia material. De este modo logar la institucionalización y volver susceptibles de evaluación a las prácticas a partir de la "calidad", la "responsabilidad social", la "pertenencia", la "transparencia”, el "carácter verde", etc. 
g) Hablar de patrones de actividad y con ello inferir un dinamismo acotado a partir de la adecuación de los objetos y la tecnología mediante un discurso que permita referir la naturaleza de las innovaciones (así como catalizar las paradojas generadas entre discurso y operación) en función de un acoplamiento permanente a variantes para construir nuevas verdades instituidas por el mercado.

h) Finalmente, el discurso reificador, como mito moderno lleva a definir al sujeto como un individuo que centra su relación e identidad en función de sus hábitos de consumo.

\section{Referencias Bibliográficas}

Alonso, E. (2005). La era del consumo. España: Siglo XXI.

Baudrillard, J. (2012). La sociedad de consumo. España: Siglo XXI.

Castells, M. y Himanen, P. (2016). Reconceptualización del desarrollo en la era global de la información. México: Fondo de Cultura Económica.

Cassirer, E. (1988). Antropología filosófica. México: Fondo de Cultura Económica. Colección Breviarios.

Foucault, M. (2002). El orden del discurso. España: Tusquets.

Ibáñez, J. (2012). Por una sociología de la vida cotidiana. España: Siglo XXI.

Illich, I. (2015). Obras Reunidas. Vol. I. México: Fondo de Cultura Económica.

Laclau, E. (2014). "Sobre los nombres de Dios" en Los fundamentos retóricos de la sociedad. México: Fondo de Cultura Económica.

Lindstrom, M. (2010). Buy-ology. Estados Unidos: Crown Business.

Mc Luhan, M. y Powers, B. (1989). La Aldea Global, transformaciones en la vida y los medios de comunicación mundiales en el siglo XXI. España: Gedisa.

Marx, K. y Engels, F. (1974). La ideología alemana. España: Grijalbo.

Oxford. (2010). Advanced learners dictionary. Inglaterra: Oxford University Press.

Weber, M. (2009). La ética protestante y el espíitu del capitalismo. Edición electrónica. Recuperado de https://fortunatti.files.wordpress.com/2015/04/la-etica-protestante-y-el-espiritu-del-capitalismo.pdf

Winner, L. (1987). Tecnología Autónoma. España: Gustavo Gili.

\section{Referencias hemerográficas en línea}

Ciudad en movimiento. (2014) Recuperado de http://ciudadenmovimiento.org/ movilidad-metropolitana-para-ciudades-escala-humana/

http://www.fimevic.df.gob.mx/problemas/ldiagnostico.htm

Mobile lives forum. (2011). "The mobility of tomorrow, theses and controversies" Recuperado de http://en.forumviesmobiles.org/meeting/2013/08/22/introduction-1117

Redacción - PuroMarketing Marketing, Publicidad, Negocios y Social Media en Español (2014). Recuperado de: http://www.puromarketing.com/88/22677/movimientos-anticonsumo-consumidores-rebelan-contra-marcas.html 
http://www.livescience.com/46817-smartphones-lower-conversation-quality.html (consultado el 16/05/2017)

http://feelmotor.com/coche-electrico-llega-para-quedarse-parte-1/ 